\title{
REVIEW
}

\section{Management of Asthma in Adults: Current Trends and Future Directions}

\author{
A. K. Bello and C. H. Njoku \\ Department of Medicine, Usmanu Danfodiyo University, Sokoto, Nigeria \\ Reprint requests to: Dr C. H. Njoku, Department of Medicine, College of Health Sciences, Usmanu Danfodiyo \\ University, P. M. B. 2254, Sokoto, Nigeria.E-mail: chnjoku2000@yahoo.com
}

\begin{abstract}
Bronchial asthma has witnessed a significant increase in its prevalence in the past decade. Considerable morbidity and significant mortality has been associated with it and this has been matched by increased scientific research into new methods of therapy to supplement or replace the traditionally known treatment modalities. A search for old and new literature on asthma management in adults necessitated forage in the library for old works and an internet search into relevant websites to download several works on asthma from which those relevant to this article were selected. Evidences supporting current asthma therapies including some non-pharmacological measures of intervention and alternative approaches were highlighted. Some novel interventions that may be useful in the future management of asthma were discussed. Some novel therapeutic agents acting on specific components of the inflammatory pathways in asthma are emerging. The future management of asthma may involve the use of these newer agents in combination with more established therapies. For successful management of asthma, patient's education and involvement are essential.
\end{abstract}

Key words: Bronchial asthma, management, adults

\begin{abstract}
Résumé
Ll'asthme bronchique a connu une augmentation significative à son fréquence au cours de la décennie passée. On l'avait associer avec une morbidité considérable et une mortalité significative et cellesci ont été égaler avec une recherche scientifique augmentée sur des nouvelles méthodes thérapeutiques pour supplementer ou remplacer les modalités du traitement connu traditionnellement. Une cherche pour l'ancienne ou la nouvelle littérature sur la gérance de 1 ; asthrue chez les adultes a nécessite un fourrage dans la bibliothéque pour des anciens travaux aussi qu'une cherche sur l'internet aux websites pertinent pour rétirer plusieurs travaux sur l'asthme. C'est à partir de ces travaux que ceux qui sont pertinent à cet article sont selectionés. Les preuves en faveur des thérapies actuelles de l'asthme y inclus quelques mesures pharmacologique d'intervention et des autres approches sont souliognées. Quelques interventions nouvelles qui peuvent être utile dans l'avenir pour la gérance de l'asthme sont aussi discutées. Quelques nouvelles agents thérapeutiques qui agir sur les composantes spécifiques des chemins inflamatoires en asthme s'émerge. Dans l'avenir la gérance de l'asthme peut entrainer l'emploie de ces nouveaux agents en association avec les thérapies les plus établir. Pour réussir à la gérance de l'asthme, l'education et la participation du malade est essential.
\end{abstract}

Mots clés: L’asthme bronchique, la gérance, les adultes

\section{Introduction}

The past decades have witnessed a spectacular increase in the prevalence of asthma globally, with associated significant use of healthcare resources. As far back as 1860, Henry Hyde Salter, a Physician at Charing Cross Hospital in London described asthma as paroxysmal dyspnoea of a peculiar character with intervals of healthy respiration in between attacks. ${ }^{1-3}$
He drew attention to the musical rhonchi that characterised asthmatic bronchoconstriction, and identified its cellular basis, which was only fully elucidated after the development of eosin stain by Paul Ehrlich in 1875. ${ }^{4}$ The pathological basis was further described by Huber and Koessler in 1922. 5 imilarly, another significant milestone is the characterisation of its trigger factors by Sir William Osler in the early part of the $19^{\text {th }}$ century. ${ }^{6}$ 
Asthma is associated with variable airflow obstruction, airway hyper-responsiveness, and chronic airway inflammation. It can cause considerable morbidity and a significant mortality. It is defined as reversible airway obstruction associated with inflammation and bronchial hyper-responsiveness. ${ }^{7}$ The airway hyper-responsiveness is induced by a variety of local stimuli involving biochemical pathways of histamine, leukotrienes and prostaglandins. Various risk factors are associated with the development of asthma. These include familial predisposition, maternal smoking, ethnicity, socio-economic status and gender (male sex). ${ }^{7,8}$

National and international guidelines have developed a stepwise approach to management, with treatment increment until asthma control is achieved and stepped down once control has been maintained for several months. ${ }^{7,8}$ Currently available antiinflammatory and bronchodilator drugs are very effective and a good asthma control can be achieved for most patients using these agents. A significant minority, however, will have more severe persistent asthma which is difficult to manage and which may require alternative approaches. New drugs which improve control and outcome, with minimal side effects, or improve compliance are therefore needed. Some new classes of drugs, which may fill these roles, are currently under investigation. This review aims to discuss the evidence supporting current asthma therapies including some non-pharmacological measures of intervention, and alternative approaches where appropriate, and finally discuss some novel interventions under development that may be useful in the future management of asthma.

\section{Lifestyle Modification and Other Non- Pharmacological Strategies in the Management of Asthma}

Changes in attitude, behaviour and lifestyle may play a significant role in the management of asthma. ${ }^{9,10}$

\section{Smoking}

Cigarette smoking in adults with asthma is associated with an accelerated decline in lung function, increased symptoms severity and exacerbation of frequency of attacks in addition to impaired response to inhaled corticosteroids. ${ }^{11}$ Although studies confined to populations of patients with asthma have not been done, smoking cessation clearly has a number of important health benefits which are likely to be particularly important to patients with pre-existing respiratory disease. ${ }^{12}$ Appropriate counselling should therefore be given to all patients with asthma who smoke and pharmacological treatments such as nicotine replacement therapy may be relevant.

\section{Patient involvement}

Involving patients in their asthma management plans, particularly those that include written advice for patients to follow should symptoms and/or peak flow readings deteriorate, have been shown to reduce hospital admissions for asthma and are recommended in some current guidelines. ${ }^{7,8}$ How this can be applicable in our setting with low literacy rates remain to be determined.

\section{Avoidance of allergen}

The exposure of patients with atopic asthma to the allergens that they are sensitive to has been shown to increase asthma symptoms and airway hyperresponsiveness and to cause bronchoconstriction. Studies of allergen control measures in infancy have shown reductions in respiratory symptoms, but it remains to be determined if such measures will prevent the development of atopy and asthma in adulthood. ${ }^{13}$

\section{Immunotherapy}

Allergy specificity and reaction have been described in asthmatics, and its targeting in management may improve outcome. 14 Allergen specific immunotherapy, or desensitisation, involves the administration of specific allergen extracts via subcutaneous injections of increasing concentration with the aim of inducing immunological tolerance. The process may work by generating interleukin-10 producing regulatory $\mathrm{T}$-cells. This has been found to be particularly useful in allergic rhinitis but has also been shown to improve symptoms and airway responsiveness in patients with allergic asthma. ${ }^{15}$ Overall the benefits appear to be modest, but desensitisation therapy can be labour intensive, and is associated with life threatening anaphylaxis.

\section{Pharmacological interventions}

Most management guidelines have recommended graded interventions of therapy according to severity of symptoms and frequency of attacks. 7,8

\section{Mild Asthma}

Evidence-based management here revolves around whether the asthma is mild intermittent or persistent. Mild intermittent asthmatics are those in whom symptoms occur less than once a week and have nocturnal symptoms $\leq 2$ per month. Their peak expiratory flow rate (PEF) is $\geq 80 \%$ of predicted value and shows $<20 \%$ variability. They are asymptomatic and have normal PEF between attacks. In mild intermittent asthma, the mainstay of therapy is still the use of Inhaled short acting $\beta_{2}$-agonists which are shown to be effective in bronchodilation. $7,8,16$ Their mechanism of action is thought to occur primarily by the relaxation of airway smooth muscle cells, but they also increase mucociliary clearance. They do not have any effective anti-inflammatory activity and should be used for symptom relief when required. Their regular use provides no additional benefit and may even be harmful. ${ }^{16}$ The use of more than one canister of short acting $\beta_{2}$-agonists per month has been associated with poorly controlled disease and should therefore alert the prescriber to the need for increased regular anti-inflammatory treatment. 
Mild persistent asthmatics are those in whom symptoms occur more than or equal to once a week but less than once a day. They have nocturnal symptoms more than twice a month while their PEF values are more than or equal to $80 \%$ of predicted value and show 20-30\% variability. In this group corticosteroids are currently the most effective antiinflammatory agents for the treatment and inhaled corticosteroids are currently recommended for all patients with persistent asthma who require short acting $\beta_{2}$-agonists more than once per day or those with intermittent asthma who experience severe exacerbations. ${ }^{7,8}$ They exert their anti-inflammatory effects through a diverse range of mechanisms including the activation of the glucocorticoid receptors, leading to the regulation of transcription of target genes, and the direct inhibition of a range of inflammatory cells, particularly eosinophils. Studies have consistently shown that treatment with regular inhaled corticosteroids results in significant improvements in airway inflammation in asthma. ${ }^{17}$ There is also epidemiological evidence from cohort and case-control studies showing that regular low dose inhaled corticosteroids reduce both hospital admissions and asthma deaths. ${ }^{18}$ A recent study of patients with mild, apparently well controlled asthma showed that the addition of regular low dose inhaled corticosteroids resulted in significant reduction in asthma exacerbations compared with the control group. ${ }^{19}$ These marked benefits, coupled with the low incidence of side effects, have led some to argue that inhaled corticosteroids should be given to all but the mildest patients. It is not yet fully known whether long term treatment with inhaled corticosteroids alters the natural history of asthma, or protects against decline in lung function. Long term prospective studies of the effects of regular inhaled corticosteroids on the decline in lung function in adults are needed to address this important issue.

In-addition, the cromones agents by inhalation, has been used as controller therapies in mild persistent asthma. Though mechanism of action is not fully understood, they are believed to suppress IgEmediated inflammatory responses and may inhibit inflammatory cells. ${ }^{20}$ However, they appear to be rather less effective than low dose inhaled corticosteroids and their long term effects on airway inflammation are unknown. The use of these agents in adults has therefore largely been superseded by the introduction of low doses of inhaled steroids for the majority of patients with persistent asthma. ${ }^{21}$

\section{Moderate Persistent Asthma}

This refers to patients who use $\beta_{2}$ agonist daily because of daily attacks and who have night time symptoms more than once a week. Their PEF values are more than $60 \%$ and less than $80 \%$ of predicted value and shows variability of more than $30 \%$. Such patients may have been receiving treatment with low dose inhaled corticosteroids and still have sufficient symptoms to justify a step up along the treatment ladder. There are an increasing number of treatment options for this group of patients. Long acting $\beta_{2}-$ agonists (e.g. salmeterol and formoterol) are currently generally recommended as the first choice for patients who have symptoms that persist despite regular inhaled corticosteroids. Salmeterol is a partial agonist of the $\beta_{2}$-receptors while formoterol is a full agonist. Both appear to have similar clinical effects, but formoterol has a more rapid onset of action. As with short acting $\beta_{2}$-agonists, these agents work primarily via the relaxation of airway smooth muscles, with additional effects on mast cells and vascular permeability, but without significant antiinflammatory activity. This lack of anti-inflammatory activity precludes their use as first line agents in asthma and current guidelines recommend that they are only prescribed alongside regular inhaled corticosteroids. ${ }^{7,8,22}$ Long acting $\beta_{2}$-agonists have been shown to improve day time and night time symptoms and reduce the need for rescue short acting ß2-agonists.In a randomised controlled trial of 852 patients treated with low dose inhaled corticosteroids (the FACET study) the addition of formoterol to inhaled low or high dose budesonide improved symptoms and lung function and reduced the rate of acute exacerbations. ${ }^{23}$ In-addition, the OPTIMA study in patients with milder disease suggested that the addition of formoterol resulted in greater reductions in exacerbation frequency than doubling the dose of inhaled corticosteroids. ${ }^{24}$ One important concern with long acting $\beta_{2}$-agonists is that subjects recruited into many clinical trials are carefully selected and therefore not fully representative of the patients seen in everyday clinical practice.

The earlier approach to patients with persistent symptoms despite low doses of inhaled corticosteroids was to increase the corticosteroid dose, but the evidence for this is somewhat inconsistent. While some studies have demonstrated clear dose related improvements in symptoms and lung function, 23, 25 others have not demonstrated clinically important benefits with moderate or high doses. ${ }^{26}$ Overall the beneficial effects of increasing the dose of inhaled corticosteroids appear to be modest and may be largely outweighed by the increased risk of side effects.

The next group of agents are the leukotriene receptor antagonists which are capable of markedly inhibiting exercise induced bronchoconstriction and the various responses to inhaled allergen. ${ }^{27-}$ ${ }^{29}$.Moreover, when added to as required short acting B2-agonists, clinical trials have shown improvement in lung function. ${ }^{30}$ Clinical trials have also shown evidence of efficacy in patients taking high doses of inhaled steroids, and the introduction of montelukast has been shown to allow a reduction in the dose of inhaled corticosteroid without loss of asthma control. 31 The effectiveness of the addition of leukotriene antagonists compared with increasing the dose of inhaled corticosteroids in patients with persistent symptoms, however, has not yet been fully addressed.

In-addition, high up the ladder is theophylline which has been in use for many years as 
a bronchodilator, but due to adverse effects, it has often been reserved for use in patients with more severe asthma. Recent interest has been in the use of theophylline at lower doses where the risk of side effects is minimised. The combination of low dose inhaled corticosteroids and theophylline has been shown to result in comparable asthma control as higher doses of inhaled corticosteroids and may provide slightly greater improvements in lung function. ${ }^{32}$ Following a meta-analysis, long acting $\beta_{2^{-}}$ agonists are shown to be superior to theophylline in patients taking low doses of inhaled corticosteroids and result in fewer side effects as well. ${ }^{33}$ However, unlike long acting $\beta_{2}$-agonists, theophylline has been shown to have anti-inflammatory activity and may therefore be more beneficial in some patients.

\section{Severe Persistent Asthma}

This refers to patients with limited physical activity due to continuous symptoms. Night time symptoms are frequent and their PEF values are less than or equal to $60 \%$ of predicted values with a variability of more than $30 \%$. This group of patients have persistent symptoms despite appropriate treatment for moderate persistent asthma. It is imperative in this group of patients to ensure that the persistent symptoms are due to asthma rather than other aggravating factors such as rhinitis or gastro-oesophageal reflux and to assess compliance with existing therapy. Once these issues have been resolved, current guidelines recommend a step-up in treatment, usually with high doses of inhaled corticosteroids in combination with long acting $\beta_{2}$-agonists, leukotriene antagonists, theophylline, oral $\beta_{2}$-agonists, or a combination of these agents. ${ }^{7,8}$ There have been no randomised controlled studies comparing these different treatment options in this group of patients and therefore additional therapy should be instituted on a trial basis and discontinued if there is no objective evidence of benefit. ${ }^{34}$

A further group of patients continue to have severe persistent asthma that remains difficult to control despite the measures outlined above. In these circumstances treatment with oral corticosteroids, usually in the form of daily prednisolone, may be required to minimise symptoms and prevent severe asthma exacerbations. While courses of oral corticosteroids are unquestionably a vital part of the management of acute exacerbations, careful consideration should be made before they are administered on a long term basis since there is a high risk of significant adverse effects. When needed, the lowest dose which maintains asthma control should be given. Prophylactic therapy for osteoporosis should be considered and patients should be monitored for the development of hypertension, diabetes, cataracts, glaucoma, and adrenal suppression. Similarly, obesity, thinning and bruising of the skin, and myopathy are also important concerns. Other corticosteroid sparing agents that include methotrexate, gold, and cyclosporine can be used in some instances. Although there is some evidence that these agents have steroidsparing effects in asthma each has its own safety concerns and their use should be limited to specialist units. ${ }^{35,36}$

There is also need for individualised treatment plans, required for different settings due to differences in circumstances regarding clinical presentation, and even in terms of personnel and resources. For instance, the severity of symptoms in asthma differs in pattern across the globe in epidemiology, risk profile and manifestations. ${ }^{37}$ Relevant guidelines have evolved to suit different settings even in some developing countries as South Africa. ${ }^{39}$

\section{Future Therapies}

This involves the use of such agents as Anti-IgE monoclonal antibody. The hypersensitivity type 1 immunoglobulin, IgE has a significant role in the development of allergic diseases in atopic subjects, and particularly asthma. ${ }^{14}$ Its suppression is therefore a potential target in the management of atopic asthma. A monoclonal anti-IgE antibody, omalizumab, which blocks the interaction of $\mathrm{IgE}$ with mast cells and basophils, has been developed. This agent given as subcutaneous injection at doses titrated to serum IgE levels, resulted in improved symptom control in a series of patients with resultant fewer exacerbations, and even a greater reduction in inhaled corticosteroid doses with no apparent adverse effects. ${ }^{40}$ This is an important future treatment of patients with atopic asthma.

The development of monoclonal antibodies to interleukin-5 has been widely acknowledged. This is based on the principle that the eosinophils are a characteristic inflammatory response cells in asthma. The inhibition of the cytokine interleukin-5, responsible for the maturation and release of this group of cells in the bone marrow represents another potential treatment. It has been shown that the humanised anti-interleukin-5 monoclonal antibody SB-240563 was able to reduce the sputum eosinophilia after allergen challenge when given intravenously, though without effect on the early or late fall in $\mathrm{FEV}_{1}$, or on airway responsiveness. ${ }^{41}$

More recently, the role of human recombinant interleukin-12 and interleukin-4 receptor antagonists in the armamentarium of management of asthma are being investigated.Interleukin-12 is a macrophagederived cytokine that can suppress eosinophilic inflammation by modulating T-lymphocyte responses. In several studies it has been shown to suppress eosinophilic inflammation with no associated improvements in airway hyper-responsiveness. ${ }^{42} \mathrm{It}$ awaits further characterisation and development.

Interleukin-4 is another key cytokine in the development of airway inflammation that has been targeted in the search for novel asthma therapies by the use of its antagonists. Some initial reports have shown that this drug may reduce the deterioration in symptoms and the reduced lung function that follows after withdrawal of inhaled corticosteroids. ${ }^{43}$ 


\section{Conclusion}

Despite the recent advancement in understanding of the pathophysiology and targets for therapeutic interventions in asthma, the use of inhaled corticosteroids is still the cornerstone of treatment in chronic asthma. Steroids are effective in improving eosinophilic airway inflammation, lung function and also control asthma symptoms in most patients. But some patients will still require additional therapy. There is a range of effective additional treatments available. It is vital to target treatments to patients who are most likely to respond through identification of individual treatment goals and careful assessment of likely underlying pathophysiology. In patients with more severe asthma, close monitoring of airway inflammation is required for optimal management.

Currently, some novel therapeutic agents acting on specific components of the inflammatory pathways in asthma are emerging as discussed. The future management of asthma may well involve the use of these newer agents in combination with more established therapies, after their further development and establishment of efficacy. In another but equally important dimension, patient education and involvement is an essential component of successful asthma management. ${ }^{44}$ Current management approaches require patients and families to effectively carry on with complex pharmacologic regimens, institute environmental control strategies, detect and self-treat most asthma exacerbations, and communicate appropriately with health care providers. Doctors should train patients to gain the motivation, skill, and confidence to control their asthma. Research shows that asthma education can be cost-effective and can reduce morbidity for both adults and children, especially among the high-risk patients, with appropriate lifestyle intervention. ${ }^{44,45}$

\section{References}

1. Salter HH. On asthma: its pathology and treatment. Churchill, London, 1860

2. Salter HH. An analysis of a hundred and fifty unpublished cases of asthma No.1. The Influence of sex and age in determining the liability to asthma. Lancet 1866; ii: 90-91

3. Salter HH. Lectures on dyspnoea Lecture 3.Lancet 1865;ii:475-8.

4. Hirsch J, Hirsch BI. Paul Ehrlich and the discovery of eosinophils. In: Mahmoud AAF, Austen KF (eds). The eosinophil in health and disease. Grune and Stratton, New York, 1980:323

5. Hubert HL, Koessler KK. The pathology of bronchial asthma. Arch Intern Med 1922; 30:689

6. Osler W. Bronchial asthma. In: Principles and practice of medicine. Appleton, New York, 1892:497-501

7. British Thoracic Society. Scottish intercollegiate guidelines network. British guidelines on asthma management. Thorax 2003;58 (suppl 1): 11-94
8. Global initiative for asthma. Global strategy for asthma management and prevention. National Heart, Lung and Blood Institute, 199: publication No. 95-3659

9. Erhabor GE, Aghanwa HS, Ndububa D. Patients attitude towards asthma in Ile-ife. Niger $\mathbf{J}$ Med 2003; 12:206-210

10. Jones A, Pill R, Adams S. Qualitative study of views of health professionals and patients on guided self management plans for asthma. BMJ 2000; 321:1507-510

11. Siroux V, Pin I, Oryszczyn MP, et al. Relationships of active smoking to asthma and asthma severity in the EGEA study. Epidemiological study on the genetics and environment of asthma. Eur Resp J 2000;15:470477

12. Ulrik CS, Lange P. Cigarette smoking and asthma. Monaldi Arch Chest Dis 2001;56:349353

13. Custovic A, Simpson BM, Simpson A, et al. Effect of environmental manipulation in pregnancy and early life on respiratory symptoms and atopy during first year of life: a randomised trial. Lancet 2001;358:188-193

14. Onyemelukwe GC, Shakib F, Saeed TK, et al. RAST-Specific IgE in Nigerian asthmatic patients. Ann Allergy 1986;56:167-170

15. Abramson MJ, Puy RM, Weiner JM. Allergen immunotherapy for asthma. Cochrane Database of Systematic Reviews 2000(2):CD001186

16. Walters EH, Walters J. Inhaled short acting beta2-agonist use in asthma: regular vs as needed treatment. Cochrane Database of Systematic Reviews 2000(4):CD001285

17. Djukanovic R, Wilson JW, Britten KM, et al. Effect of an inhaled corticosteroid on airway inflammation and symptoms in asthma. Am Rev Resp Dis 1992;145:669-674

18. Donahue JG, Weiss ST, Livingston JM, et al. Inhaled steroids and the risk of hospitalization for asthma. JAMA 1997;277:887-891

19. Suissa S, Ernst P, Benayoun S, et al. Low-dose inhaled corticosteroids and the prevention of death from asthma. N Engl J Med 2000;343:332326

20. Diaz P, Galleguillos FR, Gonzalez MC, et al. Bronchoalveolar lavage in asthma: the effect of disodium cromoglycate (cromolyn) on leukocyte counts, immunoglobulins, and complement. J Allergy Clin Immunol 1984; 74:41-8.

21. Edwards AM. Sodium cromoglycate (Intal) as an anti-inflammatory agent for the treatment of chronic asthma. Clin Exp Allergy 1994;24:612623

22. Lazarus SC, Boushey HA, Fahy JV, et al. Longacting beta2-agonist monotherapy vs. continued therapy with inhaled corticosteroids in patients with persistent asthma: a randomized controlled trial. JAMA 2001;285:2583-2593

23. Kesten S, Chapman KR, Broder I, et al. A threemonth comparison of twice daily inhaled formoterol versus four times daily inhaled 
albuterol in the management of stable asthma. Am Rev Resp Dis 1991;144(3 pt 1):622-625

24. O’Byrne PM, Barnes PJ, Rodriguez-Roisin R, et al. Low dose inhaled budesonide and formoterol in mild persistent asthma: the OPTIMA randomized trial. Am J Resp Crit Care Med 2001;164(8 pt 1):1392-1397

25. Greening AP, Ind PW, Northfield M, et al. Added salmeterol versus higher-dose corticosteroid in asthma patients with symptoms on existing inhaled corticosteroid. Allen and Hanburys Limited UK Study Group. Lancet 1994;344:219_ 224

26. Adams NP, Bestall JB, Jones PW. Inhaled beclomethasone versus placebo for chronic asthma. Cochrane Database of Systematic Reviews 2000(4):CD002738

27. Finnerty JP, Wood-Baker R, Thomson H, et al. Role of leukotrienes in exercise-induced asthma: inhibitory effect of ICI 204219, a potent leukotriene D4 receptor antagonist. Am Rev Resp Dis 1992;145:746-749

28. Ige OM, Onadeko BO. An open study to evaluate the safety and efficacy of Zafirlukast in patients with mild to moderate asthma in Ibadan, Nigeria. West Afr J Med 2001;20:220-226

29. Chukwu C, Okpapi J, Ige MO, Obodo JO. Efficacy and safety of Zafirlukast in the management of mild to moderate asthma. West Afr J Med 2000;19:111-119

30. Spector SL, Smith LJ, Glass M. Effects of 6 weeks of therapy with oral doses of ICI 204,219, a leukotriene D4 receptor antagonist, in subjects with bronchial asthma. ACCOLATE asthma trialists group. Am J Resp Crit Care Med 1994;150:618-623

31. Pizzichini E, Leff JA, Reiss TF, et al. Montelukast reduces airway eosinophilic inflammation in asthma: a randomized, controlled trial. Eur Resp J 1999;14:12-18

32. Evans DJ, Taylor DA, Zetterstrom O, et al. A comparison of low-dose inhaled budesonide plus theophylline and high-dose inhaled budesonide for moderate asthma. $\mathrm{N}$ Engl $\mathrm{J}$ Med 1997;337:1412-1418

33. Wilson AJ, Gibson PG, Coughlan J. Long acting beta-agonists versus theophylline for maintenance treatment of asthma. Cochrane Database of Systematic Reviews 2000(2):CD001281

34. Mahajan P, Okamoto LJ, Schaberg A, et al. Impact of fluticasone propionate powder on health-related quality of life in patients with moderate asthma. J Asthma 1997; 34:227-234

35. Aaron SD, Dales RE, Pham B. Management of steroid-dependent asthma with methotrexate: a meta-analysis of randomized clinical trials. Resp Med 1998;92:1059-1065

36. Lock SH, Kay AB, Barnes NC. Double-blind, placebo-controlled study of cyclosporin A as a corticosteroid-sparing agent in corticosteroiddependent asthma. Am J Resp Crit Care Med 1996;153:509-514

37. Falade AG, Olawuyi F, Osinusi K, Onadeko BO. Prevalence and severity of symptoms of asthma, allergic rhino-conjunctivitis and atopic eczema in secondary school children in Ibadan, Nigeria. East Afr Med J 1998 ;75:695-698

38. Kayantao D, Toloba Y, Kamissoko M, et al. Epidemiological, clinical and progressive aspects of asthma observed at Bamako, Mali. Sante 2001;11:101-103

39. Lalloo UG, Bateman ED, Feldman C, et al. Guideline for the management of chronic asthma in adults--2000 update. South African pulmonology society adult asthma working group. S Afr Med J 2000;90(5 Pt 2):540-541, 544-552

40. Soler M, Matz J, Townley R, et al. The anti-IgE antibody omalizumab reduces exacerbations and steroid requirement in allergic asthmatics. Eur Resp J 2001;18:254-261

41. Leckie MJ, ten Brinke A, Khan J, et al. Effects of an interleukin-5 blocking monoclonal antibody on eosinophils, airway hyper-responsiveness, and the late asthmatic response. Lancet 2000;356:2144-2148

42. Bryan SA, O'connor BJ, Matti S, et al. Effects of recombinant human interleukin-12 on eosinophils, airway hyper-responsiveness, and the late asthmatic response. Lancet 2000;356:2149-21453

43. Borish LC, Nelson HS, Corren J, et al. Efficacy of soluble IL-4 receptor for the treatment of adults with asthma. J Allergy Clin Immunol 2001;107:963-970

44. Clark NM, Evans D, Zimmerman BJ, et al. Patient and family management of asthma: theory-based techniques for the clinician. $\mathbf{J}$ Asthma 1994; 31:427-435

45. Parker SR, Mellins RB, Sogn DD. NHLBI workshop summary. Asthma education: a national strategy. Am Rev Resp Dis 1989; 140:848-853 